\title{
Unexpected Malignancy Rate of 1630 Hysterectomies Performed for Benign Indications: A 10-year Retrospective Analysis
}

\author{
(1) Berrin Göktuğ KADIOĞLU,' (1) Ayşe Nur AKSOY,' (1) Sevilay AKALP ÖZMEN, ${ }^{2}$ \\ (1) Paşa ULUĞ, ${ }^{3}$ (D) Özkan AYDIN ${ }^{4}$
}

'Department of Obstetrics and Gynecology, University of Health Sciences, Erzurum Regional Training and Research Hospital, Erzurum-Turkey

2Department of Pathology, Ataturk University Faculty of Medicine, Erzurum-Turkey

${ }^{3}$ Department of Obstetrics and Gynecology, Binali Yıldırım University Faculty of Medicine, Erzincan-Turkey

${ }^{4}$ Department of Pathology, University of Health Sciences, Erzurum Regional Training and Research Hospital, Erzurum-Turkey

\begin{abstract}
OBJECTIVE
Hysterectomy is one of the most common operations in gynecology. This study aimed to investigate the incidence of occult gynecologic malignancies in women undergoing hysterectomy for benign indications.

\section{METHODS}

In this retrospective study, the medical records of patients who underwent hysterectomy for benign indications between 2009-2019 were evaluated using the hospital's electronic system.

\section{RESULTS}

During the study period, 1630 cases underwent hysterectomy for benign indications. The mean age of the patients was $48.4 \pm 6.9$ years. The most common indications for hysterectomy were leiomyoma $(n=788$, $48.3 \%)$ and abnormal uterine bleeding $(n=539,33.1 \%)$. In the final histopathological evaluation results, malignancy was identified in 12 cases $(0.73 \%)$, and the mean age of these cases was $50.41 \pm 12$ years. These malignancies included four leiomyosarcomas (33.33\%), one endometrial sarcoma (8.33\%), two endometrial adenocarcinomas (16.66\%), four ovarian carcinomas (33.33\%), and one ovarian fibrosarcoma (8.33\%). Preoperative endometrial sampling was performed in 1160 cases $(71.16 \%)$. All of the occult malignant cases had preoperative endometrial sampling and no malignancy was observed in the endometrial pathology results.
\end{abstract}

\section{CONCLUSION}

Unexpected malignancy rate in women who underwent hysterectomies for benign indications was $0.73 \%$, and $58.3 \%$ of them were related to the uterus, and $41.6 \%$ were related to ovarian tissues. Occult uterine and ovarian malignancies may be observed in hysterectomies performed for benign indications. Detailed preoperative evaluation is essential to avoid the increased risk of mortality and morbidity caused by late diagnosis of malignancy.

Keywords: Benign; hysterectomy; indication; malignancy; pathology.

Copyright $\odot$ 2021, Turkish Society for Radiation Oncology 


\section{Introduction}

Hysterectomy is one of the most common operations in gynecology.[1] The majority of hysterectomies are performed for benign indications, such as abnormal uterine bleeding, uterine fibroids, adenomyosis, endometriosis, uterine prolapse, pelvic inflammatory disease, and chronic pelvic pain.[2,3] Hysterectomy may be performed abdominally (open, laparoscopic and robotic) or vaginally.[4,5] Although open abdominal hysterectomy is the most common method, laparoscopic and robotic hysterectomies have been preferred in recent years because these techniques offer less bleeding, early mobilization, shorter hospital stay, and cosmetic recovery.[5] Vaginal hysterectomy is the surgical removal of the uterus through the vagina is usually preferred in women with uterine prolapse. This technique provides fewer complications, a shorter hospital stay, and a faster recovery compared with abdominal hysterectomy. $[2,4,5]$

Endometrial sampling is usually used to identify a possible malignant pathology in the endometrium. Recent studies reported that routine endometrial sampling is unnecessary in patients undergoing hysterectomy for benign conditions in the absence of clinical findings suggestive of endometrial malignant pathology.[6,7] Although endometrial biopsy results are benign, unexpected uterine malignancies were incidentally reported in hysterectomy specimens in patients who underwent hysterectomy for benign indications. $[8,9]$

This study aimed to investigate the incidence of occult gynecologic malignancies in women undergoing hysterectomy for benign indications. For this purpose, we evaluated the final pathologies of hysterectomy specimens performed for benign indication and their compatibilities with preoperative endometrial sampling results.

\section{Materials and Methods}

This study was conducted approving by the Clinical Research Ethics Committee of Ataturk University, Medical Faculty, Erzurum, Turkey. Due to the retrospective design of this present study, signed informed consent was not obtained from participants. The medical records of patients who underwent hysterectomy for benign indications in Erzurum Nenehatun Hospital between 2009-2019 were evaluated using the hospital's electronic system. Before surgery, blood biochemical analyzes, including liver enzyme values, complete blood count, clotting tests, and tumor markers and electrocardiography and telecardiography were performed on all patients. At the same time, all patients were evaluated by the anesthesiologist preoperatively. The most suitable surgical method among abdominal (open, laparoscopic, robotic) or vaginal hysterectomy techniques was chosen based on the patient's preference, physical examination and clinical findings. Patients 40 years and older with benign endometrial biopsy results and who underwent a hysterectomy due to benign indications were included. Patients diagnosed with atypia or malignancy in cervical biopsy or endometrial biopsies were excluded from the study. Patients whose frozen section was reported as malignant during surgery were excluded from this study. Also, cases performed hysterectomy for a malign reason or obstetric indication were excluded. The patients' age, indications for hysterectomy, endometrial biopsy and pap smear results, hysterectomy methods, and histopathological results of hysterectomy specimens were recorded.

The data were analyzed with Statistical Package for Social Sciences 13.0 for Windows package software (SPSS Inc., Chicago, IL, USA). A descriptive statistical analysis was performed, and mean \pm standard deviation, percentages and frequencies values were used.

\section{Results}

During the study period, 1630 patients who underwent hysterectomy for benign indications were included. The data in the medical records of these cases were evaluated retrospectively. The mean age of the patients was $48.4 \pm 6.9$ years. One thousand two hundred thirty-five patients (75.76\%) underwent a total abdominal hysterectomy, 194 patients (11.90\%) underwent a total laparoscopic hysterectomy, 50 patients underwent $(3.07 \%)$ robotic hysterectomy and 151 patients (9.27\%) underwent vaginal hysterectomy (Table 1). Hysterectomy was performed as a primary indication for uterine myoma $(\mathrm{n}=788,48.3 \%)$, abnormal uterine bleeding $(n=539,33.1 \%)$ and uterine prolapse $(n=133$, 8.2\%) (Table 2). Preoperative endometrial sampling was performed in 1160 cases $(71.16 \%)$, and pathology results are presented in Figure 1. The proliferative endometrium was the most common with $43.87 \%$, it was determined endometrial polyp as $22.5 \%$, and chronic endometritis as $14.31 \%$, endometrial hyperplasia as $6.72 \%$, secretory endometrium as $5.77 \%$, irregular proliferative endometrium as $3.44 \%$, atrophic endometrium as $1.81 \%$ and insufficient material as $1.55 \%$. Bilateral or unilateral salpingoooferectomy was performed in 


\begin{tabular}{lcc}
\hline Table 1 & Operation types in cases & \\
Operation & $\mathbf{n}$ & $\%$ \\
\hline TAH & 1235 & 75.76 \\
TLH & 194 & 11.90 \\
RH & 50 & 3.07 \\
VH & 151 & 9.27 \\
BSO or USO & 1002 & 61.47 \\
\hline
\end{tabular}

Results were presented as $\mathrm{n}, \%$. TAH: Total abdominal hysterectomy; TLH: Total laparoscopic hysterectomy; RH: Robotic hysterectomy; VH: Vaginal hysterectomy; BSO: Bilateral salpingo-oophorectomy; USO: Unilateral salpingo-oophorectomy

\begin{tabular}{lcc} 
Table 2 & Clinical indications in cases & \\
\hline Indication & $\mathbf{n}$ & $\%$ \\
\hline Leiomyoma & 788 & 48.36 \\
Abnormal uterine bleeding & 539 & 33.06 \\
Uterine prolapse & 133 & 8.15 \\
Endometrial hyperplasia & 103 & 6.33 \\
Ovarian cysts & 43 & 2.63 \\
Cervical dysplasia & 15 & 0.92 \\
Chronic pelvic pain & 9 & 0.55 \\
\hline
\end{tabular}

Results were presented as $\mathrm{n}, \%$

1002 (61.47\%) of 1630 cases. Final histopathology results of specimens are given in Figure 2 and Table 3. Leiomyoma was observed to be the most common with $63.19 \%$. In the final histopathological evaluation results, malignancy was identified in 12 cases $(0.73 \%)$, and the mean age of these cases was $50.41 \pm 12$ years. These malignancies included four leiomyosarcomas (33.33\%), one endometrial sarcoma (8.33\%), two endometrial adenocarcinomas $(16.66 \%)$, four ovarian carcinomas (33.33\%), and one ovarian fibrosarcoma (8.33\%) (Table $4)$. Since malignancy was not suspected in the Doppler ultrasonographic examination, none of these seven patients with fibroids had Magnetic Resonance Imaging. However, leiomyosarcoma was reported in four of these patients in the final histopathological evaluation. All of the occult malignant cases had preoperative endometrial sampling, and no malignancy was observed in the endometrial pathology results. However, endometrial sarcoma was reported in a patient and endometrial adenocarcinoma was reported in two patients in the final histopathological evaluation. The pap smear results of all patients diagnosed with occult cancer were negative for intraepithelial lesion or malignancy. Occult ovarian cancer was identified in five patients. All of these patients had normal serum CA 125 levels preoperatively.

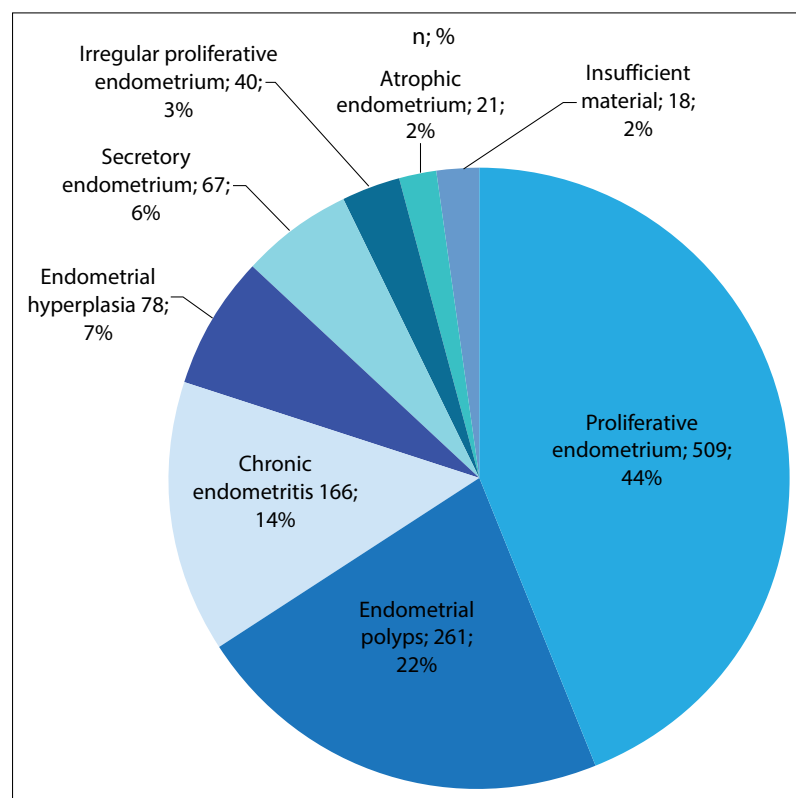

Fig. 1. Pathology reports of patients with endometrial sampling $(n=1160)$.

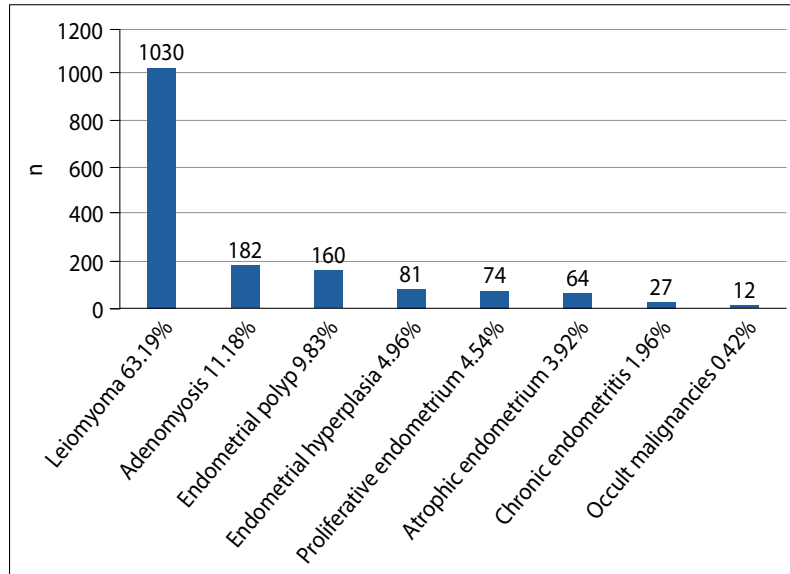

Fig. 2. Final histopathology results of hysterectomy specimens.

Interestingly, the patient whose final pathology was reported as ovarian fibrosarcoma had no ovarian cyst detected using preoperative transvaginal ultrasonography. In the other four cases reported occult ovarian carcinomas, three cases had no ovarian mass in the transvaginal ultrasonographic examination preoperatively. One case had a $6 \mathrm{~cm}$ right ovarian cystic mass with normal serum CA 125 levels. Although the intraoperative frozen section report of this patient was benign, the ovarian fibrosarcoma was reported in the final histopathological examination (Table 4). 


\section{Discussion}

The objective of this study was to investigate the incidence of unexpected gynecological malignancies diagnosed after hysterectomy for benign indications. We analyzed 1630 women who underwent hysterectomy for benign indications. Among these women, 1160 (71.16\%) of them had an endometrial sampling. The incidence of unpredictable gynecological cancer was

\begin{tabular}{|c|c|c|c|}
\hline Table 3 & \multicolumn{3}{|c|}{$\begin{array}{l}\text { Final histopathology results of oophorectomy } \\
\text { specimens }\end{array}$} \\
\hline Ovaries & & $\mathbf{n}$ & $\%$ \\
\hline \multicolumn{2}{|c|}{ Simple cyst or normal ovarian tissues } & 881 & 87.92 \\
\hline \multicolumn{2}{|c|}{ Serous cystadenoma } & 54 & 5.38 \\
\hline \multicolumn{2}{|c|}{ Endometriosis/Endometrioma } & 23 & 2.29 \\
\hline \multicolumn{2}{|c|}{ Adenofibroma } & 16 & 1.59 \\
\hline \multicolumn{2}{|c|}{ Dermoid cyst } & 13 & 1.29 \\
\hline \multicolumn{2}{|c|}{ Mucinous cystadenoma } & 10 & 0.99 \\
\hline \multicolumn{2}{|c|}{ Malignancy } & 5 & 0.49 \\
\hline
\end{tabular}

Results were presented as $n, \%$
$0.73 \%$, and $58.3 \%$ of them were related to the uterus, and $41.6 \%$ were related to ovarian tissues.

Hysterectomy is one of the most commonly performed major surgical interventions worldwide.[10] The most common indications for hysterectomy include uterine fibroids, abnormal uterine bleeding, adenomyosis, endometriosis, uterine prolapse, pelvic inflammatory disease, and chronic pelvic pain.[2,3] In this current study, $48.34 \%$ of benign hysterectomies were performed for uterine fibroids and $33.06 \%$ for abnormal uterine bleeding. On the other hand, among women found to have occult uterine malignancy, hysterectomy was also performed as a primary indication for uterine fibroids (58.33\%) and abnormal uterine bleeding (33.33\%). All of the occult malignant cases had preoperative endometrial sampling and the proliferative endometrium was the most common with $66.66 \%$. Unlike our results, the most common indications for hysterectomy were reported as abnormal bleeding (47\%) and postmenopausal bleeding (15\%) in Parsons et al.s[11] study. Similar to our findings, Topdagi et al.[9] reported that $57.42 \%$ of benign hys-

Table 4 Characteristics of patients whose final histopathological results were reported as malignant

\begin{tabular}{|c|c|c|c|}
\hline Indication for hysterectomy & $\begin{array}{l}\text { Endometrial biopsy } \\
\text { results }\end{array}$ & Operation & $\begin{array}{l}\text { Final pathology } \\
\text { results }\end{array}$ \\
\hline 1. Uterine myoma & Proliferative endometrium & $\mathrm{TAH}+\mathrm{BSO}$ & $\begin{array}{l}\text { Leiomyosarcoma, normal } \\
\text { ovarian tissues }\end{array}$ \\
\hline 2. Abnormal uterine bleeding & Proliferative endometrium & $\mathrm{TAH}+\mathrm{BSO}$ & $\begin{array}{l}\text { Endometrioid adenocar } \\
\text { cinoma, normal ovarian tissues }\end{array}$ \\
\hline 3. Abnormal uterine bleeding & $\begin{array}{l}\text { Simple non-atypical } \\
\text { endometrial hyperplasia }\end{array}$ & $\mathrm{TAH}+\mathrm{BSO}$ & $\begin{array}{l}\text { Endometrioid adenocarcinoma, } \\
\text { normal ovarian tissues }\end{array}$ \\
\hline 4. Abnormal uterine bleeding & Proliferative endometrium & $\mathrm{TAH}+\mathrm{BSO}$ & $\begin{array}{l}\text { Endometrial stromal sarcoma, } \\
\text { normal ovarian tissues }\end{array}$ \\
\hline 5. Uterine myoma & Proliferative endometrium & $\mathrm{TAH}+\mathrm{BSO}$ & $\begin{array}{l}\text { Leiomyosarcoma, normal } \\
\text { ovarian tissues }\end{array}$ \\
\hline 6. Uterine myoma & Proliferative endometrium & $\mathrm{TAH}+\mathrm{BSO}$ & $\begin{array}{l}\text { Leiomyosarcoma, normal } \\
\text { ovarian tissues }\end{array}$ \\
\hline 7. Uterine myoma/Ovarian cyst & Endometrial polyp & $\mathrm{TAH}+\mathrm{BSO}$ & $\begin{array}{l}\text { Leiomyoma, Mucinous adeno } \\
\text { carcinoma in ovary }\end{array}$ \\
\hline 8. Anormal uterine bleeding & Proliferative endometrium & TAH+BSO & $\begin{array}{l}\text { Adenomyosis, Clear cell carci } \\
\text { noma focus in the ovary }\end{array}$ \\
\hline 9. Uterine myoma & $\begin{array}{l}\text { Simple non-atypical } \\
\text { endometrial hyperplasia }\end{array}$ & $\mathrm{TAH}+\mathrm{BSO}$ & $\begin{array}{l}\text { Leiomyoma, Endometrioid } \\
\text { adeno carcinoma in the ovary }\end{array}$ \\
\hline 10. Chronic pelvic pain & Proliferative endometrium & $\mathrm{TAH}+\mathrm{BSO}$ & $\begin{array}{l}\text { Adenomyosis, Fibrosarcoma } \\
\text { in ovary }\end{array}$ \\
\hline 11. Uterine myoma & Chronic endometritis & $\mathrm{TAH}+\mathrm{BSO}$ & $\begin{array}{l}\text { Leiomyosarcoma, normal } \\
\text { ovarian tissues }\end{array}$ \\
\hline 12. Uterine myoma & Proliferative endometrium & $\mathrm{TAH}+\mathrm{BSO}$ & $\begin{array}{l}\text { Leiomyoma, Endometrioid ad } \\
\text { enocarcinoma in ovary }\end{array}$ \\
\hline
\end{tabular}


terectomies were performed for uterine myoma and/or treatment-resistant menometrorrhagia.

Studies showed that abnormal uterine bleeding is the most common symptom in women with endometrial cancer.[12,13] Thus, routine endometrial sampling is recommended in all symptomatic women.[7] However, preoperative endometrial sampling has a low predictive value for the diagnosis of uterine sarcomas.[14] In a retrospective study, Pessoa et al.[12] analyzed 893 women who underwent uterine curettage and reported the risk of endometrial malignancy significantly higher in women aged $\geq 50$ years than that younger women. The authors proposed routine endometrial sampling in all patients 50 years of age or older for those undergoing hysterectomy. Also, they reported a significant association between irregular uterine bleeding and the presence of endometrial malignancy. In this current study, preoperative endometrial sampling was performed in 1160 cases $(71.16 \%)$ and the proliferative endometrium was the most common with $43.87 \%$. On the other hand, occult uterine malignancy was identified in seven $(0.42 \%)$ cases and ovarian malignancy was identified in five $(0.30 \%)$ cases in the final histopathological evaluation of specimens. The incidence of unpredictable endometrial cancer was $0.18 \%$. Interestingly, all of the malignant cases had preoperative endometrial sampling, and the results were benign. In seven of these malignant cases, endometrial biopsy was reported as a proliferative endometrium. Our results are compatible with the results of Yuk et al.s study.[15] They analyzed 12.850 women who underwent a hysterectomy for benign conditions. In their study, the incidence of unexpected uterine malignancy and endometrial cancer after hysterectomy was reported as $0.19 \%$ and $0.12 \%$, respectively. In another study, Topdagi et al.[9] reported unexpected malignancy in 13 of the 1050 patients $(1.23 \%)$ who underwent hysterectomy for benign indications. In a recent study, Parsons et al.[11] performed a retrospective review of $6981 \mathrm{pa}-$ tients underwent hysterectomy for benign reasons. The incidence of unexpected endometrial carcinomas was reported as $0.19 \%$. In another study containing a large sample group, Desai et al.[16] identified 229.536 adult women who underwent hysterectomy for benign indications during ten years. The incidence of occult uterine cancer was $0.96 \%$, including $0.75 \%$ with endometrial carcinoma and $0.15 \%$ with uterine leiomyosarcoma. Also, the incidence of occult ovarian cancer was observed as $0.19 \%$ in their study. These results are in line with our results.

\section{Limitations of the Study}

This present study revealed the possibility of malignant outcomes in hysterectomies performed for benign indications. This study is important for the literature in terms of revealing data at a secondary referral center during a ten-year period. Also, this study reveals the importance of a detailed preoperative evaluation for the early diagnosis of malignancies. However, there is a limitation in our study. Unfortunately, we had no information on patients' postoperative follow-up revealing potentially results caused by delays in diagnosis and treatment of occult malignancies. Since there is no intensive care unit in our hospital, follow-up and treatment of these patients were carried out in tertiary referral centers. Multicentre studies involving a large number and analyzing long-term follow-up data of patients are required.

\section{Conclusion}

In conclusion, the unexpected malignancy rate in women who underwent hysterectomies for benign indications was $0.73 \%$, and $58.33 \%$ of them were related to the uterus, and $41.6 \%$ were related to ovarian tissues. Occult uterine and ovarian malignancies may be observed in hysterectomies performed for benign indications. A detailed preoperative assessment should be performed on all patients, considering potential occult malignancies. Patients who are scheduled for hysterectomy with benign indications should be informed in detail preoperatively about the final pathology reports may be malignant.

Peer-review: Externally peer-reviewed.

Conflict of Interest: The authors have no conflicts of interest to declare.

Ethics Committee Approval: The study was approved by the Ataturk University Faculty of Medicine Clinical Research Ethics Committee (No: 13, Date: 07/05/2020).

Financial Support: The authors declared that this study has received no financial support.

Authorship contributions: Concept - B.G.K., A.N.A., P.U., S.A.Ö., Ö.A.; Design - A.N.A., B.G.K.; Supervision S.A.Ö., Ö.A., P.U.; Funding - A.N.A., B.G.K.; Materials A.N.A., B.G.K.; Data collection and/or processing - B.G.K., A.N.A., P.U., S.A.Ö., Ö.A.; Data analysis and/or interpretation - B.G.K., A.N.A., P.U., S.A.Ö., Ö.A.; Literature search - B.G.K., A.N.A., P.U., S.A.Ö., Ö.A.; Writing - B.G.K., A.N.A., P.U., S.A.Ö., Ö.A.; Critical review - B.G.K., A.N.A., P.U., S.A.Ö., Ö.A. 


\section{References}

1. Spilsbury K, Semmens JB, Hammond I, Bolck A. Persistent high rates of hysterectomy in Western Australia: a population-based study of 83000 procedures over 23 years. BJOG 2006;113(7):804-9

2. ACOG Committee Opinion No. 444: choosing the route of hysterectomy for benign disease. Obstet Gynecol 2009;114(5):1156-8.

3. Wright JD, Herzog TJ, Tsui J, Ananth CV, Lewin SN, $\mathrm{Lu}$ YS, et al. Nationwide trends in the performance of inpatient hysterectomy in the United States. Obstet Gynecol 2013;122(2 Pt 1):233-41.

4. Johnson N, Barlow D, Lethaby A, Tavender E, Curr E, Garry R. Surgical approach to hysterectomy for benign gynaecological disease. Cochrane Database Syst Rev 2006;(2):CD003677.

5. Madhvani K, Curnow T, Carpenter T. Route of hysterectomy: a retrospective, cohort study in English NHS Hospitals from 2011 to 2017. BJOG. 2019;126(6):795-802.

6. Nicholls-Dempsey L, Kamga-Ngande C, Bélisle S, Lapensée L, Roy G, Tremblay C, et al. Endometrial biopsy in an outpatient gynaecological setting: overinvestigation. J Obstet Gynaecol Can 2018;40(10):1309-14.

7. Hanligil E, Ekici MA. Is it necessary to perform an endometrial sampling prior to hysterectomies for benign conditions? Exp Biomed Res 2019;2(2):76-84.

8. Mahnert N, Morgan D, Campbell D, Johnston C, AsSanie S. Unexpected gynecologic malignancy diagnosed after hysterectomy performed for benign indi- cations. Obstet Gynecol 2015;125(2):397-405.

9. Topdagi Yilmaz EP, Cimilli Senocak GN, Topdagi YE, Aynaoglu Yildiz G, Kumtepe Y. Incidence of occult malignancies identified during hysterectomies performed for benign indications. J Gynecol Obstet Hum Reprod 2020;49(3):101620.

10. Neis KJ, Zubke W, Fehr M, Römer T, Tamussino K, Nothacker M. Hysterectomy for benign uterine disease. Dtsch Arztebl Int 2016;113(14):242-9.

11. Parsons LHP, Pedersen R, Richardson DL, Kho KA. The prevalence of occult endometrial cancer in women undergoing hysterectomy for benign indications. Eur J Obstet Gynecol Reprod Biol 2018;223:108-12.

12. Pessoa JN, Freitas AC, Guimaraes RA, Lima J, Dos Reis HL, Filho AC. Endometrial assessment: when is it necessary? J Clin Med Res 2014;6(1):21-5.

13. Khafaga A, Goldstein SR. Abnormal uterine bleeding. Obstet Gynecol Clin North Am 2019;46(4):595-605.

14. Bansal N, Herzog TJ, Burke W, Cohen CJ, Wright JD. The utility of preoperative endometrial sampling for the detection of uterine sarcomas. Gynecol Oncol 2008;110(1):43-8.

15. Yuk JS, Kim LY, Kim SH, Lee JH. The incidence of unexpected uterine malignancy in women undergoing hysterectomy for a benign condition: a national populationbased study. Ann Surg Oncol 2016;23(12):4029-34.

16. Desai VB, Wright JD, Gross CP, Lin H, Boscoe FP, Hutchison LM, et al. Prevalence, characteristics, and risk factors of occult uterine cancer in presumed benign hysterectomy. Am J Obstet Gynecol 2019;221(1):39.e1-39.e14. 